\title{
Los sistemas de signos en Rapa Nui (siglo XVIII)
}

\author{
Rapa Nui's sign systems ( $18^{\text {th }}$ century $)$ \\ Rolf Foerster G. ${ }^{1}$
}

\begin{abstract}
“... no es importante que la cosa descrita muestre un dios extinguido por el que podría interesarse gente de formación humanista, sino el dios representado en la piedra represente una creación-cosa que todavía sigue enviando señales" (P. Sloterdijk, Has de cambiar tu vida, 2012)
\end{abstract}

\section{Resumen}

Posiblemente no haya lugar y sociedad más inseparable de sus "objetos", los maoi y los rongo-rongo, que Isla de Pascua. Desde el siglo XVIII Europa se fascina con en esos monumentos, con su capacidad aurática, acrecentada por una comunidad que eliminó las condiciones materiales y discursivas de su construcción (sólo conservó sus relatos míticos). Así la agencia de los objetos, su mana, entró de lleno en el juego entre la comunidad y los europeos, transformando ese vínculo en una relación triangular.

Palabras claves: Isla de Pascua, moai, rongo-rongo, aura, zona de contacto.

\begin{abstract}
Perhaps there is no other place and society more inseparable from its 'objects', the moai and the rongo-rongo, than Easter Island. Since the $18^{\text {th }}$ century Europe has been fascinated with those monuments, with their aura, which was emphasised by the communitarian elimination of the material and discursive conditions of their construction (only mythical accounts are kept). Consequently, objects' agency (their mana) entered fully in the interplay between the community and the Europeans, transforming that link in a triangular relation.
\end{abstract}

Keywords: Easter Island, moai, rongo-rongo, aura, contact zone

\section{Introducción}

Hay concordancia, desde el primer relato europeo en el siglo XVIII, que el sistema de signos más relevante o dominante en Te pito te Henua (el ombligo del mundo) era/es el relativo a los moai. Los cuatro diarios de la expedición holandesa de Jacob Roggeveen, de 1722, lo mencionan de forma destacada; isla y monumentos parecen ser una sola cosa. No obstante, 50 años más tarde el

${ }^{1}$ Profesor de antropología de la Universidad de Chile, Facultad de Ciencias Sociales, Departamento de Antropología. 
sistema de signos parece cambiar de valoración por la presencia de los europeos (tangatahiva), con su mana, sus barcos, sus bienes y sus armas mortales. Te pito te Henua deviene Rapa Nui y/o Isla de Pascua por ese intercambio, una relación histórica, donde no sólo emergen nuevos sistemas de signos (los rongo-rongo), sino que también los existentes son marcados por una heteroglosia propia de la "zona de contacto" y de la mímesis (una isla construida, donde los diarios de viaje y sus lectores son parte de ella). ${ }^{3}$

Cientos de estatuas megalíticas están dispuestas en el borde del mar mirando hacia el interior, otras tantas están a punto de salir de la cantera Rano Raraku, algunas, y de forma excepcional, se encuentran en su interior. No todas están en altares: $a h u$. Su visibilidad, desde fuera y desde dentro no tiene puntos ciegos, su presencia parece cubrirlo todo. Nadie escapa a ese sistema, que exige ser narrado. Así, las más recientes lecturas han sido la de Peter Mason con sus "siete maneras de ser moai" (2005), o la de Diamond (2007) y sus seguidores (Flenley y Bahn 2002): como los "signos de los tiempos: la autodestrucción". Es esta capacidad evocadora de sus signos (ya sea en pie o derrumbados) ${ }^{4}$ que ha hecho de la isla un lugar único en el mundo.

\footnotetext{
2 “[...] la expresión zona de contacto es con frecuencia sinónimo de frontera colonial. Pero esta última forma conserva una perspectiva europea expansionista, ya que la frontera es una frontera sólo con respecto a Europa. La 'zona de contacto' desplaza el centro de gravedad y el punto de vista hacia el espacio y el tiempo del encuentro, al lugar y al momento en que individuos que estuvieron separados por la geografía y la historia ahora coexisten en un punto, el punto en que sus respectivas trayectorias se cruzan. El término contacto pone en primer plano las dimensiones interactivas e imprevistas de los encuentros coloniales, tan fácilmente dejados de lado o hasta suprimidas por los relatos de conquistas y dominación contados desde el punto de vista del invasor. Una perspectiva 'de contacto' destaca que los individuos que están en esa situación se constituyen en y a través de su relación mutua" (Pratt 2011: 34). Para nosotros una comprensión más acabada de esos vínculos pasa por los objetos y su agencia, de este modo los monumentos, su aura, su mana, son el tercer término del triángulo.
}

${ }^{3}$ Si usáramos los términos de Paul Ricouer diríamos que las tramas narrativas europeas del siglo XVIII y de los rapanui recogidas en el siglo XX (Mímesis II), son posibles gracias a la estructura de la acción presente en los moai, en su universo simbólico y temporal (Mímesis I). Los moai fueron hechos para ser narrados y el lector, al leer esas tramas, queda atrapadoconvocado por su enigma (Mímesis III). Es el círculo hermenéutico. Said como Foucault y los estructuralistas se quedan en Mímesis II, pero para rescatar la dimensión rapanui en la trama hay que ir al círculo entre las tres mímesis.

${ }^{4}$ La lectura fálica ha estado presente en las mismas fuentes rapanui, éstas consideran a las estatuas como "símbolos fálicos, y que la forma de su cabeza y cuello pretendía darles apariencia de pene, sugiriendo la fertilidad y la vida engendradas por los ancestros deificados. Aunque la etimología de la palabra Moai es incierta, pienso que se origina a partir de su función básica, y que en tal caso podría derivar de mo, que significa "para", y de $a i$, que es el término para "copulación", pero que también se puede traducir como "fertilidad" y "reproducción"” (Edwards s.f: 378). 
El "obligo del mundo" esta así ornamentado, monumentalizado, por este sistema de signos. No se trata de un sistema que apunte a la representación sino a la significación. ${ }^{5}$ El paisaje de la isla es lo que es gracias a ese universo; se lo lee a través de él. Pero no sólo el paisaje, también la historia de Pascua, desde el siglo XVIII, al menos, y hasta hoy está marcada, signada por esa mediación simbólica. La auto valoración y la de los "extranjeros", ha pasado por ese sistema. Para los rapanui su vinculación con ellos está dada por su ontología, donde nada queda fuera del vínculo genealógico (de ahí la posibilidad de significar a los antepasados) como también hacer visible su poder (mana).

La fuerza de este sistema de signos funciona (al menos para los europeos) independientemente de la lengua hablada. No obstante, este sistema de signos tuvo/tiene la virtud de su dimensión aurática, propia del "arte". Los moai son reconocidos, y también son diferenciados de la estatuaria griega, egipcia, mexicana, andina, etc. La forma-contenido del arte rapanui es un significante que se presta para un "juego" en torno a lo "misterioso", pero también al poder. Nos enfrentamos - para usar los términos de Alfred Gell (1998) - a la agencia de los objetos materiales. ${ }^{7}$

Veamos este despliegue en el siglo XVIII. Constataremos cómo esas narrativas gravitan sobre el sistema y también cómo en ese encuentro, en ese vínculo los rapanui responden haciendo emerger nuevos sistemas de signos (rongo-rongo) y de intercambios.

\section{2, la expedición de Jacob Roggeveen}

De los cuatro diarios que se conocen de la expedición de Roggeveen, dos de ellos se publicaron en el siglo XVIII: el Anónimo, en 1728, y el Carl Friedrich Behrens, en 1739. Veamos que nos dice el primero sobre los "monumentos".

El Anónimo liga los "moai” a lo religioso - ídolos - y al culto, pero en

\footnotetext{
5 "Ese artista no puede o no quiere reproducir íntegramente su modelo y se ve obligado, pues, a significarlo. En lugar de ser representativo, el arte aparece así como un sistema de signos" (Lévi Strauss 2006: 70).

${ }^{6}$ Para Mason: "En el caso de un moai solitario y en pie, hay un antropomorfismo fundamental, pero a la vez no es una representación de una persona: la monumentalidad de su volumen, el hecho de estar tallado en un solo bloque de piedra y que ninguna de sus partes sea independiente de ese volumen, elimina la posibilidad de identificar al moai con un individuo. Es precisamente este juego de identidad y diferencia lo que provoca lo misterioso (el termino freudiano es unheimlich) del moai. Y esa calidad de misterioso se refuerza por su aislamiento: desprovisto de contexto, privado de 'compañía', resiste al acto de interpretarlo de la misma manera en que lo colosal, lo que supera la medida del cuerpo humano, resiste al acto de medirlo" (Mason 2005: 13).

${ }^{7}$ Lo que Gell destaca es cómo "un artefacto es capaz de afectar a las personas, movilizando respuestas emocionales, generando ideas y provocando una variedad de acciones y procesos sociales" (Martínez 2012: 173).
} 
su descripción no trata de los cientos de "piedras" sino sólo de dos. Una, que "reposaba sobre la tierra", tenía una extensión "inconmensurable"; sobre ésta "yacía la otra piedra, que era de tal extensión y altura que incluso siete de los nuestros con brazos extendidos apenas hubieran sido capaces de rodearla" y "alrededor de la punta de esta piedra estaba cortada o tallada la forma de la cabeza de un hombre, adornada con una guirnalda, la que estaba armada a la manera de un trabajo de marquetería, hecha de pequeñas piedras, de una manera no tan impropia" (Anónimo 1728: 69).

Para el Anónimo se trata de dos "ídolos" - donde el más grande era llamado Taurico y el otro Dago -, a los cuales se les "tenía gran respeto": "se aproximaban a ellos con gran veneración, concretamente con bailes, gritos, saltos y aplausos, de la misma manera que leemos en las sagradas escrituras, que los hijos de Israel adoraron el becerro de oro que Aarón erigió” (Anónimo 1728: 69).

A pesar del vínculo de la comunidad con sus ídolos, esta no los habría construido, lo que genera una situación tanto más escandalosa si consideramos que, para el Anónimo, los habitantes de la Isla eran una suerte de gigantes ("el doble de alto y ancho que el más grande de los nuestros": unos "hijos de Goliat" y "tan proporcionados [...] que cada uno de ellos podía haber pasado por Hércules"): [...] así que parecía para mí, y para todos los otros, imposible que esta piedra pudiera haber sido levantada y colocada sobre la otra por los habitantes de estas islas, tan grandes y fuertes como pudiesen ser (Anónimo 1728: 69).

El Anónimo inaugura así una doble lectura sobre los monumentos: por una lado, los liga a un culto, el idolátrico (pensado bajo el código del Antiguo Testamento) y, por otro, que esos ídolos no fueron construidos por la comunidad (por un desfase "técnico" que desvaloriza nuevamente a la comunidad).

Hay, así, en la isla una ausencia que fue presencia (otra comunidad), una presencia que se manifiesta en unos ídolos cuyos constructores ya no están. Nos enfrentamos a una historia oculta, un misterio cuya resolución, a partir de relatos del siglo XIX y XX, es la guerra y el conflicto entre dos pueblos, los Hanau-momoko (gente delgada) y los Hanau-eepe (gente corpulenta) y donde los primeros, primitivos habitantes de la isla, eliminaron a la casi totalidad de los segundos. Para Englert, uno de los más destacados investigadores del siglo $\mathrm{XX}$, la construcción de los moai y de los $a h u$, puede deberse a uno o a otro de estos grupos. Así, para Arturo Teao (1938:79), un Hanau-momoko, fueron ellos los constructores; para los descendientes de los Hanau-eepe, en cambio, sólo ellos los habrían esculpido.

Destaquemos, por un lado, el tema de la diferenciación interna, que se puede traducir en guerra o en un conflicto violento en el seno de la comunidad; por otro, la disputa de las partes (de los linajes) por la autoría de los monumentos.

La segunda relación, la de Behrens, retoma el problema - de lo sagrado 
y la autoría - y le da un primer giro. Por un lado, los ídolos ya no son dos, sino una multitud: "vimos una gran multitud de ídolos a lo largo de la costa" (Behrens 1739: 72). Por otro, el tema del culto aparece en la descripción del primer encuentro que tienen con un "nativo":

Uno de los habitantes llegó hasta nosotros en una canoa navegando hasta dos millas. Le hicimos señas de subir a bordo de nuestra nave Almirante, donde lo recibimos bien. Empezamos por darle un trozo de tela con el fin de que se cubriera, pues estaba completamente desnudo. También le ofrecimos coral y otras bagatelas. Todo, junto con un pescado seco, los prendió a su cuello. Su cuerpo estaba enteramente pintado con toda suerte de figuras. Era moreno, sus orejas eran extremadamente largas y pendían hasta sus hombros. Aparentemente, había llevado pesados pendientes que habían producido el alargamiento. Lo mismo se ve practicar a los negros del país del Gran Mogol. Era bastante alto, fuerte y robusto, de buena fisonomía. Era alegre, vivaz y de gestos agradables mientras hablaba. Le dimos un vaso de vino, pero en lugar de beberlo se lo tiró a los ojos, lo que nos sorprendió bastante. Para mí, pienso que este isleño se imaginó que queríamos envenenarlo, según el uso frecuente entre indios. En seguida lo vestimos y le colocamos un sombrero, pero bien vimos que no tenía costumbre pues se sintió muy molesto. Después le dimos de comer; pero no supo utilizar ni la cuchara, ni el tenedor, ni el cuchillo. Después de que fue atendido, se ordenó a los músicos hacer sonar toda clase de instrumentos. La sinfonía le produjo mucha alegría y cada vez que le tomaban la mano, comenzaba a saltar y a bailar.

En cuanto a nosotros, estábamos encantados con la venida de este isleño. Como no pudimos echar el ancla ese mismo día, lo enviamos a su casa con todos los pequeños presentes, con el fin de que los demás pudieran saber de qué manera lo habíamos recibido. Pero pareció lamentar la partida: levantó ambas manos, volvió los ojos hacia la isla y comenzó a gritar con fuerza pronunciando estas palabras: ¡Odorroga! ¡Odorroga! Le costó bastante decidirse a volver a su canoa, nos hizo entender que él deseaba permanecer en el barco y que posteriormente lo desembarcáramos en su isla. Parece que con sus gritos haya implorado a su dios, pues vimos una gran cantidad de ídolos a lo largo de la costa. (Behrens 1739: 72).

Para Roger Fischer este "habitante" o "isleño" sería un tumu ivi 'atua, un chamán, y su presencia en las naves estaría asociada al levantamientos de los tapu (tabu), la voz odorroga, correspondería a otoroka, que en viejo rapanui, es "bienvenidos" (Fischer 2006: 49). A diferencia del Anónimo, según este autor, los isleños serían gente totalmente desarmada, de allí el valor que le otorga Behrens a los ídolos (como armas): "Empero, me di cuenta de que, en caso de 
ataque, estas pobres gentes se confían enteramente en la ayuda de sus ídolos, erigidos en gran cantidad a lo largo de las costas" (Behrens 1739: 74). Estamos frente a una afirmación conocida en la tradición polinésica: el poder las estatuas, su mana.

Estas estatuas eran todas de piedra con la figura de un hombre con grandes orejas, cuya cabeza estaba ornada con una corona; el todo realizado y proporcionado según las reglas del arte, lo que nos asombró mucho. Alrededor de estos ídolos, unos veinte o treinta pasos a la redonda, existe un piso hecho de piedras blancas. Algunos de estos habitantes servían a los ídolos con mayor devoción y celo, lo que nos hizo creer que se trataba de sacerdotes; con mayor razón pues se veía en ellos marcas distintivas: no solamente gruesas bolas pendientes de sus orejas sino que también portaban la cabeza totalmente afeitada y un bonete de plumas blancas y negras, que se parecían a las de las cigüeñas. (Behrens 1739: 74).

El "asombro" de Behrens y de sus pares frente al sistema de signos localizados a "lo largo de la costa" no es por su monumentalidad, sino por estar hecho según las "reglas del arte". Esta suerte de armonía, de congruencia, la observa también en el modo como sus habitantes han cultivado la isla, de allí que no se lamentaría vivir en ella:

Esta isla es muy apta para tomar descanso y buscar el fresco. En ella todo está labrado y cultivado, y está plena de árboles y de bosques [Tout y est cultivé \& labouré; elle est remplie de bois \& de forêts]. [...] Se elevó un viento del Oeste[...] nos vimos obligados a salir mar afuera pues no queríamos correr el riesgo de encallar. La desgracia pudo no haber sido demasiado grande ya que, si hubiéramos perdido nuestros barcos habríamos podido vivir tranquilamente en medio de estos isleños" (Behrens 1739: 74-75).

Estos son parte de los relatos y los grandes temas sobre Rapa Nui que circularán en el siglo XVIII; son lo que leerán los futuros expedicionarios y que los motivará para ir a su encuentro. Pasemos a los españoles.

\section{La expedición española, 1770 (el nuevo sistema de signos: los rongo-rongo)}

Los diarios de la expedición española de 1770 sólo se conocieron públicamente en el siglo XX: tres de ellos en inglés, en 1908, y su totalidad en español, en 1986; una suerte de resumen fue publicado en 1897 por José de Moraleda. La expedición inglesa del capitán Cook, a su vez, supo de este viaje a través de los espías que había en la corte y posiblemente obtuvieron copias de algunas de esas relaciones. 
En el contexto de este análisis, el mayor atractivo de la expedición española tiene que ver con el hecho de haber localizado con precisión la isla en los mares del sur, además de haber aportado antecedentes sobre el sistema de glifos rongorongo.

Entre las observaciones registradas son particularmente relevantes las siguientes: "Tienen por toda la Isla en particular en la orilla del mar, unos bultos grandes de piedra de figura humana: tendrán de alto como 12 varas y pienso que son sus ídolos." (Hervé 1986: 107).

En otro registro se lee:

Tienen otros de piedra de diversos tamaños, situados con las espaldas al mar a los que denominan Gemoay ${ }^{8}$, sobre cuyas cabezas tienen una piedra de color de fierro viejo a manera de canasto o brasero, y encima unas más grandes que otras colocadas en simetría: habiendo causado no pequeña admiración el ver, que sin tener máquina ni clase de instrumento para estas obras hubiesen podido colocar con tanto equilibrio sobre cuatro piedras pequeñas unos ídolos de 9 toesas (González 1986: 111).9

El oficial de la Marina Española Francisco Aguera mira hacia la isla desde su nave y observa que sobresale "una especie de árboles gruesos a imitación de pirámides en la playa, y cuasi colocados en simetría." Posteriormente, ya en tierra, se desengaña:

Hemos averiguado que los árboles que nos parecían pirámides son estatuas, o imágenes de los ídolos que adoran estos naturales, son de piedra, tan elevados, y corpulentos que parecen columnas muy gruesas, y según después averigué, examiné y tomé su dimensión, son de una pieza todo el cuerpo, y el canasto es de otra. En este tienen construida una pequeña concavidad en su superficie alta en la que colocan los huesos de sus muertos, de que se infiere que tienen ídolos, $[\ldots]$ sin poder comprender el modo con que habrán erigido esta estatua tan soberbia y mantenerla en un equilibro sobre cuatro pequeñas piedras que asientan en la basa, o pedestal que sostiene todo este gran peso. El material de la estatua es de piedra muy dura, y por consiguiente pesada, habiéndola yo examinado con una picaza despidió fuego, prueba de su solidez. El canasto es de otra piedra no tan sólida y de color de la vena del fierro, es bastante pesada, y se halla mucha en la Isla, pero semejante a la estatua, no la he visto; su construcción es muy mazorral ${ }^{10}$. En la configuración del rostro solo se manifiesta una escabazón tosca para los ojos. Las narices están medianamente sacadas, y la boca alcanza de una a otra oreja figurando una pequeña mortaja,

\footnotetext{
${ }^{8}$ He moái (nota de Mellén 1986: 111, nota 14).

${ }^{9}$ Toesa: antigua medida francesa de longitud, equivalente a 1,946 m.

${ }^{10}$ Mazorral: grosero, rudo, basto.
} 
o excavación en la piedra, el cuello tiene alguna similitud; carece de brazos, y piernas; procediendo desde el cuello para abajo en forma de un canto mal desbastado. El diámetro del canasto es mucho mayor que el de la cabeza en que asienta, y su circunferencia baja, sobresale mucho de la frente de la estatua, causando admiración esta postura sin desplomarse. De esta confusión pude salir con la investigación que hice de otra estatua pequeña, en cuya cabeza tenía figurada una a modo de mecha que debía entrar en el canasto, el que así mismo había de recibir en una especie de carlinga, o mortaja correspondiente, y de este modo se puede mantener el canasto sobresaliendo de la frente; pero la elevación de la estatua, y colocación del canasto por unas gentes que carecen de máquinas, y materiales para construirlas, causa admiración, y aun creo que la piedra de la estatua no es producto de la Isla en la que absolutamente desconocen el fierro, cáñamo y maderas gruesas. Sobre este asunto queda mucho que trabajar al discurso. Habiendo hecho la dimensión geométrica de la estatua más alta que se halla a la orilla de esta ensenada, halle que tenia de alto cincuenta y dos pies y seis pulgadas de Castilla ${ }^{11}$, incluso el canasto, que tenía cuatro pies y ocho pulgadas de la misma medida, advirtiendo que en la parte del E. de la Isla se hallan otras de más elevación, según noticias de los exploradores. Se hallan otras muchas repartidas por el terreno interior, que son como de dos o tres estados, y entre de estas se encuentran innumerables que solo constan de una pirámide, o montón de piedras mal formadas, digo colocadas, en cuya cúspide asientan una piedra redonda bañada de tierra blanca, a imitación de una calavera humana, de que se deja ver que allí tienen sus sepulcros. Las estatuas de configuración se llaman Moay, a quienes los naturales manifiestan tener mucha veneración, y se ofenden cuando nos aproximamos a ellas para reconocerlas. (Aguera 1986: 119).

Ahora bien, tanto Felipe González de Haedo como Francisco Aguera constatan una realidad: los medios para la construcción de los moais no están a la vista, de allí que el primero escriba: "habiendo causado no pequeña admiración el ver, que sin tener máquina ni clase de instrumento." Aguera se explaya más y se aventura con dos hipótesis: una, ya formulada por el Anónimo (1728), que la comunidad que ellos observan no las construyó, y la otra, que se trata de un enigma abierto al trabajo del discurso: "causa admiración, y aun creo que la piedra de la estatua no es producto de la Isla en la que absolutamente desconocen el fierro, cáñamo y maderas gruesas. Sobre este asunto queda mucho que trabajar al discurso." (Aguera 1986: 119).

Justamente de eso al parecer se trataba para la comunidad: hacer desaparecer las condiciones de producciones para aumentar su verosimilitud "maravillosa", que no fueron los hombres sus constructores, sino el mana.

${ }^{11} 1$ pie $=0,279 \mathrm{~m} . ; 1$ pulgada $=23,25 \mathrm{~mm}$. 
El hecho de no mostrar las condiciones de reproducción parece darse también en lo demográfico. A ese respecto llama la atención que los españoles constataron otro desfase: hay más hombres visibles que mujeres. ${ }^{12}$ Las cifras de la población total aventuradas por los españoles van desde las 900 a 1000 personas, según Hervé (cf. carta del Archivo Museo Naval, Madrid en Mellén 1986: 70-71), hasta 3000 según González, que escribe "Los naturales cuyo número se cree no excedan de 3000" (1986:111).

Sobre la ausencia, o la escasa presencia femenina, Francisco Aguera comenta con insistencia:

Las [mujeres] que hemos visto componen corto numero respecto a los hombres de que se puede colegir que usan de ellas en común, o tienen escondidas las propias, y esto creo será lo más cierto como se manifestó la tarde del desembarco que al pasar por la inmediación de una pequeña choza reconocimos como hasta ocho mujeres todas mozas, y no mal parecidas acompañadas de un viejo que solo las permitía asomar la cabeza a mirarnos (Aguera 1986: 122).

[...] el número de las que hemos visto es muy corto respecto a los hombres: no hemos sabido el método que observan en la propagación pero si discurrimos que las mujeres vistas serán las comunes entre ellos respecto a la facilidad con que las ofrecían y que tuviesen ocultas las legítimas" (ibidem, 131).

¿Eliminadas o escondidas? En los conflictos violentos entre pueblos y comunidades (guerras civiles), la violencia puede apuntar al exterminio del otro: eliminar a sus mujeres y sus ídolos (y si eso es así, entonces hay que cuidarlas y protegerlas). O ¿se trata del "cálculo salvaje" que esconde a muchas y muestra a pocas, que transforma a casi todas en "privadas" mientras que hace de algunas pocas "públicas"?

Si todo sistema de significación exige el paso de lo continuo a lo discontinuo, entonces las "sustracciones" en el plano del sistema moai son consistentes a las sustracciones económicas y demográficas que realizaban los rapanui. Posiblemente esté aquí una clave de que las construcciones megalíticas se abocaran a los moai y no a viviendas o palacios (¿un una variante del "fundamentalismo": todo a los antepasados-dioses poco o casi nada a los "vivos"?).

\footnotetext{
${ }^{12}$ De cuatro relaciones de la expedición holandesa solo la de Roggeveen da cuenta de este hecho: "no vimos más que 2 a 3 mujeres mayores, vistiendo una prenda desde la cintura hasta bajo las rodillas, y otra alrededor de los hombros, pero de manera tal que la piel de sus pechos colgantes estaba descubierta; pero las mujeres e hijas jóvenes no se mostraron, por lo que se cree que los celos podrían haber inducido a los hombres a esconderlas en una parte separada de la isla."
} 
Los relatos españoles tienen un atractivo adicional: introducen el sistema de signos rongo-rongo. Recordemos que la "toma de posesión" de la isla por los españoles fue "corroborada" al ser "signada" por "algunos indios":

[...] se tomó posesión con la acostumbrada formalidad y para mayor corroboración de este acto tan serio, firmaron, o signaron algunos de los indios concurrentes gravando en el documento testimonial ciertos caracteres según su estilo" (Aguera 1986: 125).

¿Hay alguna relación entre el sistema de signos-moai y los signos rongorongo? ¿Hay moai con rongo-rongo? El ave Manutara, signado en el papel de la posesión, está inscrito en la espalda del moai Hoa Hakananai'a que está en el Museo Británico. Esta capacidad traslaticia de la "escritura" la podemos observar en el cuadro de Gauguin, pintado en 1893, de su joven esposa Tehamana, titulado "los antepasados de Tehamana" (Merahi metua no Tehamana) y en cuyo fondo aparece un escrito rongo-rongo.

Pero si los moai obligan a la emergencia de la narrativa, los rongo-rongo no van a la saga y posiblemente por la misma razón: las preguntas no logran ser respondidas. Queda un significante flotando, que impide que el sistema se cierre. Esto genera una comunidad hermenéutica donde los actuales rapanui han sido convocados. ${ }^{13}$ Veamos esto con lo "signado" en la toma de posesión de la isla. En 1874 Park Harrison propuso la siguiente traducción:

The symbol to the right is assumed to be the signature of the king of the island. It stands by itself, and appears to represent one of the figures -half men and half birds- which it has been supposed symbolize chiefs.

The characters in the second or middle column may perhaps form the name of a chief next in rank; or possibly a priest. There are four signs in this column, of which the third from the top is similar to some in the tablets. The third column from the right contains eight characters. They probably, form a single name[...] (Harrison 1874:528).

A mediados de la década de 1970 Francisco Mellén ("spain's foremost historian of the Pacific", cf. Fischer 1997:3) pidió a algunos ancianos en la isla que le explicaran el sentido de esos "signos", la respuesta fue que desconocían "lo que significaban, conociendo todo lo más un par de grafemas". Un década más tarde (1984) Mellén insistió, consiguiendo, con Leonardo Pakarati (que había trabajado con Barthel), una traducción al rapanui:

\footnotetext{
${ }^{13}$ En 1970 Campbell y Silva señalaban que: "En poder de muchos isleños se encuentran hojas con signos, en que se anotan significados o traducciones. Casi no hay pascuense que no se declare saber el lenguaje rongo-rongo" (1970:175). Comunidad con "hojas con signos", donde todos declaran saber el lenguaje rongo-rongo es lo que me parece relevante, con ello la comunidad participa activamente en el intento del "desciframiento" y esto desde Monseñor Tepano hasta Mellén pasando, por supuesto, por Thomson, Routledge, Métraux, Barthel, Campbell-Silva.
} 
Tai moroki - he hanga i roto i te vai kava - ki te takatore - he papa kiroto i te kaka maika - he veri - he hue - he a mo he iri - he tu u ki te hare - he kao ta ana - he nake - koro Manu he ui.

La versión en castellano de Leonardo fue realizada por Benedicto Tuki y Kiko Paté:

Marea baja - quiere el (takatore) molusco del interior del mar - lo pone en una hoja de plátano tapado - limpio - y guardó - se lo llevó al hombro y se fue - llegó a la casa - prepara curanto -(recordando espíritu de su papá) - en la fiesta de "Manu" (pájaro)." (Mellén s.f.: 8)

Todo funcionaba a la perfección cuando Mellén solicitó al juez de la isla, Fernando Igualt Ansted, que participara en su trabajo de desciframiento. En diciembre de 1987 el juez le envió una nueva traducción de Leonardo Pakarati:

Hakapiri - i to matou ina - i te ora hoou - tapu - he iri o matu - ko ia ko to ona varu a $-\mathrm{He}$ iri ki runga ki te maunga - he hakapiri tu hunga nui - he manava more o mahatu - hanga raí.

Motivo - Tener dentro o unido - de nuestro corazón - como vida nueva - Estamos dentro - Sagrado - Vámos - juntos con tu espirítu caminando al cerro - Repartiendo - Repartiendo el corazón - quiero mucho" (Mellén s.f.: 13-14).

El comentario de Mellén frente a esta nueva versión de Pakarati fue: "Mi sorpresa fue enorme al comprobar que nada tenía que ver con lo traducido hacía tres años, lo que me recordaba a Metoro delante del Obispo Jaussen, que cada día leía los signos de la tableta de forma distinta al día anterior" (Mellén s.f.: 11).

Recientemente uno de los más prolíficos estudiosos de los rongo-rongo, Sergei Rjabchikov, propuso una lectura acorde a la de Harrison:

\section{Line 1:44: Kena}

Line 2:14 130 53: Hau Tiki-Ana-Maro

Line 3: 17-51 5426591016 74-74 15: Teke Kaimakahi [KAHI] Tinitini Roa

Taha (Kena). Hau Tiki-Ana-Maro. Teke Kaimakahi [KAHI] Tinitini Roa.'The tribal union Te Kena. The King Tiki-the Shine-the Solstice. The King Kaimakoiof the Great Crater/Light (i.e. Rapa Nui, or Easter Island)'. (Rjabchikov 1998, apud Mellén s.f.: 17).

Para Mellén esta traducción "desconcierta y deja atónito a cualquier estudioso del tema, pues nada tiene que ver con las traducciones recogidas anteriormente. Aquí, según Rjabchikov, están los nombres de los tres jefes o ariki que signaron el documento español, que recuerda lo escrito anteriormente por Harrison" (Mellén s.f.: 17-18). 
¿Cómo es posible esta variación? Una posible respuesta la encontramos en la manera como Barthel aborda la escritura rongo-rongo: ésta se encuentra a medio camino entre la pictografía y un sistema arbitrario de signos, como la escritura fonética:

[...] sistema convencional de comunicación que está dotado de un número limitado de signos, que pueden, empero, ampliarse considerablemente mediante combinaciones sujetas a reglas fijas. Este sistema por encima de la etapa de la simple pictografía, y comprende una mezcla de ideogramas simples y múltiples, distintos grados de simbolización, y signos de palabras que se usan fonéticamente para escribir nombres y rebús. Por la condensación del texto y la indicación sólo parcial del sonido, la comprensión se hace difícil, pero no imposible. (Barthel 1956:235)

Ahora bien ¿Cuál es el origen de los rongo-rongo? Para la tradición rapanui el rey fundador de Pascua, Hotu Matúa, las habría traído consigo desde Hiva; no obstante si seguimos la tesis de Fischer, las cosas toman otro carácter o dimensión: la "escritura" rapanui nace en la "zona de contacto" y en el momento "soberano", cuando españoles y rapanui "firman" el acta de posesión. Se trata de una "lección de escritura", ${ }^{14}$ donde la elite rapanui, comprendiendo la dimensión de poder (mana) que ella involucraba, crearon una escritura propia ("rude system of writing", según Routledge), signando en ella sus genealogías y relatos de creación. También es relevante aquí que en estas escrituras nada se nos diga del sistema de los moai:

Con particular expectación se indagarán las inscripciones buscando datos que hagan referencia a problemas especiales de la Isla de Pascua, tales como el culto ornitológico de Orongo, las grandes estatuas y las figuras talladas en madera. Desgraciadamente, los resultados han de ser muy escasos... Poco satisfactorias son las vagas referencias a las esculturas, sobre todo en vista de que algunas lecturas aisladas como ahu moai para una terraza funeraria ocupada con estatuas, y moai kavakava para las reproducciones esqueletarias de los espíritus de los muertos, representan sólo hipótesis de trabajo. Por lo que es posible observar en las inscripciones conservadas, hay pocas esperanzas de hallar en ellas mayor información sobre los moai. Por lo tanto, los textos grabados en las tabletas no pueden resolver el enigma de las grandes estatuas de piedra. (Barthel 1956: 237)

"La palabra rongo-rongo quiere decir recitación o leer cantando, y corresponde precisamente a la forma en que los antiguos procedían a la lectura

\footnotetext{
${ }^{14}$ Lección de escritura es la expresión que utilizó Lévi-Strauss (en Tristes Trópicos) para referirse a cómo un jefe indígena se empodera imitando frente a los suyos y a los europeos la escritura de éstos últimos.
} 
de las tabletas" (Campbell y Silva 1970:164). Nuestra amiga Angela Tepano (nieta de Juan Tepano, el informante de Routledge, Metraux y Englert) ha insistido en nuestras conversaciones sobre los Rapa Nui, que la historia de su pueblo está en el canto. Si esto es y ha sido así, entonces lo notable es que el tema de los moai - su construcción, su sentido y su derribo - no pasara por ese sistema. Esto tiene mucho sentido para la tesis de que el sistema rongo-rongo emergió en un contexto donde los rapanui habían comenzado a abandonar el sistema moai (una suerte de iconoclastia: no solo derrumbarlos sino también, en muchos casos, descabezarlos). Es lo que va a constatar la expedición inglesa de 1772 .

\section{La expedición inglesa de 1772 (del monumento a la ruina)}

La contribución de la expedición "inglesa" al sistema de signos es enorme por el acopio de información y de "giros". Posiblemente lo más relevante, desde nuestra perspectiva, es una pintura y el conjunto de grabados (su potencia aurática), uno de los cuales constata el paso del "monumento" a la "ruina", una temporalidad no presente en las otras expediciones.

Los diarios de James Cook y del joven Georg Forster, ${ }^{15}$ de la segunda expedición de Cook alrededor del mundo (1772-1775), fueron publicados en Londres en 1777; en su época fueron obras de gran relevancia editorial y de fuerte impacto en los círculos cultos europeos. Si Cook ya gozaba de fama por su primer viaje alrededor del mundo (1768-1771), esta nueva publicación, $A$ voyage towards the South Pole and round the World, lo lanzó al estrellato. La obra de Georg Forster, A Voyage round the World in His Britannic Majesty's Sloop Resolution, Commanded by Capt. James Cook (Londres 1777), traducida al año siguiente al alemán, ${ }^{16}$ fue acogida favorablemente por Goethe y su entorno, y la influencia en la vida y la obra de Alexander von Humboldt quedó plasmada en el libro Cuadros de la Naturaleza. ${ }^{17}$

Cook, en base a las relaciones de las expediciones holandesa y española, esperaba ansiosamente encontrar en Pascua lo que la tripulación necesitaba después de estar casi 13 semanas navegando por el Polo Sur. Las descripciones de la isla nos mostrarán un mundo donde dominan los campos áridos, aunque también observan "unas grandes plantaciones de cañas de azúcar"; esperaban

\footnotetext{
${ }^{15}$ George Forster (1754-1794) tenía 18 años cuando se embarcó en el segundo viaje de James Cook, en compañía de su padre, el naturalista John Reinhold Forster.

${ }^{16}$ Reise um die Welt, Berlín, 1778-80.

17 "Se concibe, de hecho, que el aspecto del Mar del Sur haya tenido algo solemne para un hombre que debe a su comercio con un compañero del capitán Cook, una parte de su saber y la dirección tomada luego por su curiosidad. Georg Forster conoció temprano mis planes de viaje en su intención general, cuando tuve la feliz suerte de visitar por primera vez Inglaterra bajo su conducta." (Cuadros de la Naturaleza, Libro VIII)
} 
encontrar porcinos y sólo pudieron comerciar unos pocos pollos; ansiaban agua dulce y solo pudieron beber un agua salobre. No pudieron entonces gozar de la abundancia natural de Tahiti, pero tampoco constataron una pobreza extrema que llevara a su población al hambre (o a la guerra).

También observaron que en la isla no existían las jerarquías de Tahiti con su corte y su reina; en Pascua la autoridad, los aree o hareekee, no se distinguían de los comunes y la razón para Georg Forster era la pobreza. Pero se trata de dos dimensiones, de dos imágenes (jerarquía y precariedad), que apuntan narrativamente al gran tema ya presente en 1722, el desfase, la "desproporción" entre "los objetos sorprendentes" - "su sombra, un poco después de las dos, era suficiente para resguardar de los rayos del Sol a toda la partida, que consistía en unas treinta personas" (Cook 1777:160) - y el "poderío actual de la nación":

De este relato es evidente, que las investigaciones más diligentes por nuestra parte, no han sido suficientes para otorgar una luz clara sobre los objetos sorprendentes que nos llamaron la atención en esta isla. Sin embargo, podríamos intentar explicar esos monumentos gigantescos, de los cuales existen grandes números en cada lugar; ya que son muy desproporcionados al poderío actual de la nación, es más razonable considerarlos como los vestigios de tiempos mejores (G. Forster 1777: 186).

Pero, cuidado, esos "vestigios" están en proceso de abandono. La descripción de Johann Reinhold Forster - padre de Georg, que participó en el segundo viaje de Cook como naturalista - es la mejor que tenemos de ese estado de cosas, de cómo aún quedaban en pie algunos y otros estaban derribados:

En la mañana el Capitán Cook envió al teniente Pickersgill, con un grupo de marineros y marinos, a los cuales el Sr. Wales, el Sr. Hodges, Sparman y yo nos asociamos, hacia el país para hacerun reconocimiento; éramos en total 27 hombres. Primero estuvimos directamente del otro lado del país bajo el cerro alto, hasta que llegamos al otro lado de la isla, y allí encontramos 7 pilares de piedra, 4 de los cuales seguían en pie, y 3 estaban derribados, quizás por un terremoto. Uno de los erguidos había perdido su gorra. Estos pilares se yerguen sobre una especie de pedestal o elevación de piedra: en algunos lados estas elevaciones están hechas de piedras regularmente labradas puestas tan regular y finamente como puede ser hecho por una nación incluso con buenas herramientas. En qué manera ingeniaron estas estructuras es incomprensible para mí, ya que no vimos herramientas con ellos. Sin embargo, la piedra de la cual estos muros e imágenes están hechos no parece ser de gran dureza, ya que es roja, cavernosa y quebradiza piedra ferrosa o Tophus. Las imágenes representan a hombres hasta la cintura, las orejas son grandes y son de alrededor de 15 pies de alto y de más de 5 pies de ancho; son malformadas y tienen una gran gorra 
sólida en su cabeza, como algunas de las viejas divinidades egipcias; la gorra que medí tenía más de 5 pies de diámetro, y observé en el centro a cada lado un agujero, como si los nativos hubiesen hecho estas piedras redondas torneándolas. Pero después vimos algunas aun más grandes, concretamente una de 17 pies de alto, y en el otro lado de la isla una de 27 pies de altura y 9 pies de ancho en la base; estaba derribada y yacía en el suelo. Estos pilares indican que los nativos fueron antiguamente un pueblo más poderoso, más numeroso y mejor civilizado; y estos son los únicos monumentos de su antiguo esplendor. (J.H. Forster 1982: 224).

Ruina, "antiguo esplendor" pero donde los monumentos aún conservan sus nombres y su valor:

Los pilares y muros cerca del lugar de anclaje y abrevadero son llamadas Hàngāa-ròa, aquéllas que nos encontramos primero en nuestra marcha eran llamadas Hàngā-to-bòw, el siguiente HangāHeève, Hàngāmāhàgā y así. Las imágenes o pilares son igualmente denominados, probablemente en honor al hombre, a cuya memoria se erigieron. Estos nombres la gente sabe y preserva. El pilar solitario cerca de Hàngā-ròāse llama Obeènā. Los primeros 7 que nos encontramos, tenían los siguientes nombres Kotomoāi, Kotomoèeree, Koohoò-oo, Moraheena, Oomareeva, Ooeenābo, Ooeenāpà. El gran pilar donde más tarde cenamos es llamado Māngā-tòto, y así los nativos preservan la memoria de sus antiguos jefes, porque verdaderamente dijeron que fueron Arèes" (ibidem, 224).

Por lo que describe esta cita, ya no se trata del relato de dos pueblos que entraron en pugna mortal, sino de sólo uno, que "antiguamente" era poderoso y ahora ya no lo es. De ahí que, como escribe Georg Forster, sea

[...] probable, que estas personas fueron antaño más numerosas, más opulentas y felices, cuando podían escatimar tiempo suficiente para halagar la vanidad de sus príncipes, al perpetuar sus nombres mediante monumentos duraderos. Los restos de plantaciones encontrados en las cumbres de las colinas, dan fuerza y apoyo a esta conjetura. No está en nuestro poder determinar por cuáles diversos accidentes una nación tan floreciente, podría ser reducida en número y degradada a su indigencia actual. (G. Forster 1777: 186).

Pero eran "realmente indigentes" o hubo una política por parte de la comunidad de mostrarse frente a los tangata hiva como carentes de recursos. ¿No había un "cálculo salvaje? Esto es notable en el registro de los "recursos humanos". Georg Forster nos describe un mundo donde la desproporción de los sexos y de las generaciones es manifiesta: 
Después del desayuno acompañé al capitán Cook y a varios oficiales atierra, donde encontramos unos doscientos habitantes reunidos, entre los cuales había catorce o quince mujeres y muy pocos niños. Era imposible para nosotros adivinar la causa de esta desproporción en el número de los diferentes sexos; pero como todas las mujeres que vimos eran muy liberales en sus favores, conjeturé en ese momento, que a las casadas y modestas, que podría suponer se formaban la mayor parte, no les importaba venir cerca de nosotros, o eran forzadas por los hombres aquedarse en sus viviendas en las zonas remotas de la isla. Esas pocas que aparecieron eran quizás las más lascivas de su sexo, que han sido encontradas en cualquier país, y la vergüenza parecía ser completamente desconocida para ellas; nuestros marineros igualmente negaron conocimiento alguno de modestia, por nada más que la sombra que el gigantesco monumento proyectaba a ellos desde el sol. (ibidem, 181).

No obstante, cuando recorren el interior observan la misma desproporción:

Todas las mujeres que vimos en distintas partes de la isla, no superaban las treinta, aunque nuestra gente la cruzó casi de un extremo al otro, sin verla menor probabilidad de que las mujeres se hayan retirado a algún lugar aislado. Si realmente no hay más de treinta o cuarenta mujeres, entre seiscientos o setecientos hombres, toda la nación está en justo camino a la completa extinción en un corto espacio de tiempo, a menos que todos nuestros principios físicos sobre la pluralidad de los maridos sean erróneos.[...]Pero esta desproporción es un fenómeno tan singular en la naturaleza humana, que no podemos sin dificultad darle crédito y de buena gana me aferraría a cualquier argumento que, aunque cargado de dificultades, pudiera restaurar la proporción entre los sexos. Es cierto que nuestro grupo no vio ningún valle o cañada aislados, en los que las mujeres pudieran haberse confinado durante nuestra estancia; [...]. Las cavernas de Islandia son lo suficientemente amplias como para contener varios miles de habitantes; y nada es más probable que, en un país volcánico similar, tales cavernas puedan solventar alojamiento para unos pocos cientos. (ibidem, 187).

Georg Forster está sin duda en lo cierto: los rapanui escondieron a la casi totalidad de sus mujeres en las cavernas, y las pocas mujeres que vieron mostraron un espíritu de Mesalina capaz de reproducir a la totalidad de los hombres que vieron. No obstante, Forster nuevamente vacila en esta tesis por el asunto de los pocos niños que observaron, para volver al argumento de "algún accidente extraordinario":

Las razones que podrían tener los pascuenses para ser más celosos de sus mujeres que los taheitianos, no las sabemos; pero estamos familiarizados con el comportamiento escandaloso y lascivo del marinero, donde quiera que tenga gran superioridad sobre el indio, como los holandeses y españoles deben haber tenido sobre el pueblo 
de Isla de Pascua. La principal objeción contra esta suposición es, sin embargo, el pequeño número de niños que allí vimos, no habiendo razón para ocultarlos de nuestros ojos, a pesar de lo que podría considerarse necesario con respecto a las mujeres. En resumen, este asunto debe permanecer sin resolver y si, de hecho, el número de mujeres es despreciable, debe haber sido disminuido por algún accidente extraordinario, que nadie, salvo los nativos podría haber explicado; pero, en todas nuestras dudas, nuestra ignorancia de su idioma nos ha impedido adquirir información alguna. (ibidem, 187).

Pero duda y se aproxima al tema político:

Es probable, que el terror con el que vieron las armas destructivas de los europeos en ese momento y durante la tardía visita de los españoles, haya sido revivido entre ellos con nuestra aparición y tuvo una influencia en su comportamiento generalmente tímido hacia nosotros; pero no cabe duda, al mismo tiempo, que hay una bondad, empatía y afabilidad en su modo de ser, lo que naturalmente les provoca tratar a sus visitantes amablemente e incluso hospitalariamente, dentro de lo que su desdichado país puede permitir. (ibidem, 183).

Georg Forster sabe que los holandeses asesinaron a parte de la población con sus "armas destructivas", sabe también y está familiarizado "con el comportamiento escandaloso y lascivo del marinero, dondequiera que tenga gran superioridad sobre el indio, como los holandeses y españoles deben haber tenido sobre el pueblo de Isla de Pascua". También intuye lo que recientemente señaló Roger Fischer:

[...] this ostensible meretricious conduct, witnessed at this time throughout Polynesia was not 'prostitution' in the Western sense, with all its social and moral connotation. It probable originated in, and in part was continued out of, the combined necessity to increase the respective descent group's holdings and to enrich its gene pool -the alter an especially enduring and status-enhancing prospect on small Pacific islands. (Fischer 2005: 75)

Recordemos que Sahlins trató este punto en su libro Islas de Historia como una suerte de teogamia polinésica, donde las palabras del sabio Orou - en Hommages à Diderot - no solo serían válidas para el caso de Tahiti, sino también para Rapa Nui:

Más robustos y sanos que ustedes, percibimos a primera vista que nos sobrepasan en inteligencia, e inmediatamente elegimos varias de nuestras mujeres e hijas más hermosas para cosechar la semilla de una raza mejor que la nuestra. Es una prueba que hemos hecho y que puede redundar en nuestro beneficio. Hemos tomado de usted y los suyos la única ventaja que podríamos tomar, y créame, con todo lo salvaje que somos, también sabemos calcular (Sahlins 1988: 25). 
¿Si el "cálculo salvaje" era aplicado a los "recursos" humanos, no se aplicó también a los recursos materiales y naturales? ¿No escondieron los rapanui también la casi totalidad de sus alimentos y sólo dieron una parte de ellos a los europeos? ¿Por qué no mostraron sus recursos de aguas en los volcanes? Y ¿mostrarse carentes no era una forma de tener un vínculo donde el intercambio le fuera ventajoso?

Cook extrajo la conclusión colonial de este estado de cosas en la isla:

Ninguna nación debe ambicionar el honor de haber descubierto esta isla, pues pocos sitios hay que tan mal se presten para el abastecimiento de buques. No hay fondeadero seguro, ni leña para combustible, ni agua dulce que merezca ser llevada a bordo. La naturaleza ha sido excesivamente parca en sus favores a este lugar, pues todo ha de ser obtenido a fuerza de trabajo. (Cook 1777: 162).

Cook muestra en este pasaje su cara pragmática, no obstante la dimensión científica que la isla les suscitaba, sus misterios - ya no solo sobre lo monumental sino también sobre sus habitantes y comunidad - era reproducidos y ampliados (dramáticamente) en sus textos y grabados y fueron un estímulo para nuevas expediciones "científicas".

\section{La expedición francesa de 1786 (¿el tema de la reciprocidad?)}

La expedición francesa, que tiene como figura central al conde de $\mathrm{La}$ Pérouse, fue pensada por las autoridades, entre muchas otras razones, para emular los viajes de Cook. Si éste último tuvo un final trágico en Hawai, La Pérouse desaparecerá misteriosamente, con sus dos naves, la Boussole y la Astrolabe, en Vanikoro el año 1788. De allí que su obra sea una reconstrucción hecha por Milet-Mureau en 1797-1798, donde se unen el diario de La Pérouse (vol. II y III ${ }^{18}$ ) y los informes de algunos de los científicos que lo acompañaban (tomo IV); además de los cuatro volúmenes, un Atlas donde hay 4 láminas sobre la isla (núms. 10, 11, 12 y 61).

El plan del viaje fue redactado con lujo de detalles por Luis XVI. En relación a los objetivos e instrucciones, la mezcla de intereses coloniales y científicos era lo dominante:

[...] complementar los notables resultados de los viajes de Cook, particularmente en lo relativo a la costa de Alaska; prospectar allí las posibilidades del comercio de las pieles; reconocer tierras nuevas y puntos de apoyo estratégicos; reunir toda clase de información científica; y vigilar las actividades inglesas, españolas y portuguesas en ultramar. (Donoso 1987: 17).

\footnotetext{
${ }^{18}$ Lo que se conoce como el diario de La Pérouse abarca sólo hasta el año 1787.
} 
No obstante, para Pascua había un tema central: el enigma planteado por los diarios de la expedición de Cook y que debía ser resuelto, no el de los moai, sino la desproporción de los sexos y sus posibles efectos destructivos, según había pronosticado Georg Forster.

Ese es el sentido de la observación sobre la Isla de Pascua: "Dans sa relâche à l'isle d'Easter ou de Pâque, il s'assurera si l'espèce humaine s'y détruit, comme on a lieu de la présumer d'après les observations et le sentiment du capitaine Cook." (La Pérouse 1798: I, 26)

Sin duda que la relación de La Pérouse está construida para dialogar y contradecir, en todo lo que podía, a las de Cook-Georg Forster. Esto aparece desde el inicio en sus observaciones sobre la Isla de Pascua:

No puedo sino arriesgar algunas conjeturas respecto de las costumbres de este pueblo, cuya lengua no comprendía y al que no he visto sino un día. Tenía sin embargo las experiencias de los viajeros que me habían precedido, conocía perfectamente sus relatos, a los cuales podría añadir mis propias reflexiones. (La Pérouse 1798) ${ }^{19}$

La Isla de Pascua pasa ahora por los textos y sus lectores; así, la expedición francesa ve a Pascua y a sus habitantes a través de las relaciones de los ingleses.

Para La Pérouse, las razones de las diferencias con respecto a la expedición inglesa serían, en primer lugar, fruto del observador, del ánimo y la expectativa con que se llegó a la Isla:

[...] este pueblo me ha parecido menos desgraciado que al capitán Cook y al señor Forster. Ellos llegaron a esta isla después de un viaje largo y penoso, faltos de todo, enfermos de escorbuto y no encontraron ni agua, ni leña, ni cerdos; algunas gallinas, bananas y patatas, son muy pobres recursos en esas circunstancias. Sus relatos llevan el sello de esta situación. La nuestra era infinitamente mejor: los tripulantes gozaban de la más perfecta salud, habíamos tomado en Chile aquello que nos era necesario para varios meses y sólo queríamos de este pueblo la facultad de hacerles el bien. (ibidem)

Pero también las diferencias serían producto ya no del observador sino de la población misma, por ejemplo, con respecto a los alimentos; a los ingleses se los habrían negado por no haber habido "consentimiento" y no por su escasez:

[...] si a este célebre navegante (Cook) le fue difícil procurarse una buena cantidad de patatas y de ñames, no fue debido a la escasez de estos comestibles sino a la necesidad de obtener el consentimiento casi general para venderlos. (ibidem)

\footnotetext{
${ }^{19}$ Los trechos de La Pérouse citados a continuación, con las observaciones sobre la Isla de Pascua, corresponden a Voyage de La Pérouse autour du monde [...] (1798), vol. II, caps. IV y V, p. 90-117.
} 
Otra razón de este trato distinto se debería a que gracias a que los ingleses se comportaron de forma "generosa", ahora la población pudo mostrarse en su casi totalidad (con lo cual de paso se demostraba lo equivocado de la observación de Forster sobre la disparidad de los sexos):

La cantidad de mujeres me ha parecido muy cercana a aquella de los hombres, he visto una mayor cantidad de niños que en ningún otro país. Aunque, sobre unos mil doscientos habitantes que nuestra llegada juntó en las cercanías de la bahía, habrían, a lo más trescientas mujeres, al respecto he conjeturado que se puede suponer que los naturales del otro extremo de la isla habrían venido a ver nuestros buques y que las mujeres, más delicadas, o más ocupadas en el cuidado de sus hogares y de sus hijos, habían permanecido en sus casas, de manera tal que sólo habíamos visto aquellas que residen cerca de la bahía. El relato del señor de Langle confirma esta opinión: él encontró al interior de la isla muchas mujeres y niños. En cuanto a nosotros, todos penetramos en esas cavernas en la que el señor Forster y algunos oficiales del capitán Cook creyeron al principio que las mujeres pudiesen estar escondidas. Se trata de casas subterráneas, de la misma forma que las que describiré más adelante y en las cuales habíamos encontrado pequeños haces de leña, el mayor de los cuales no tenía más de cinco pies de largo y no excedía las seis pulgadas de diámetro. No podemos sin embargo poner en duda que los habitantes no hubiesen escondido sus mujeres cuando fueron visitados por el capitán Cook en 1772. No puedo adivinar la razón por la que esto sucedió, y debemos tal vez a la manera generosa con que él se condujo con este pueblo la confianza que éste nos mostró y que nos ha permitido juzgar de modo más adecuado su población. (ibidem)

Lo anterior ¿le permitía a La Pérouse una observación más objetiva del sistema de los signos, de los moai? En primer lugar, se nos dice que el dibujo ejecutado por el pintor del segundo viaje de Cook, William Hodges, "ofrece muy imperfectamente lo que hemos visto" (ibidem). De acuerdo con las mediciones del ingeniero-geógrafo de la expedición de La Pérouse, Sebastien Bernizet, habría que añadir los numerosos datos sobre las medidas $\mathrm{y}$, a partir de estas, sobre las proporciones de un $a h u$, informaciones que él presenta en un cuadro sinóptico.

Y a ese respecto comenta La Pérouse:

El señor Forster piensa que son obra de un pueblo mucho más considerable del que existe hoy día, sin embargo su opinión no me parece bien fundada. El mayor de estos bustos groseros que están en estas plataformas, y que habían sido medidos por nosotros, no tiene más que catorce pies con seis pulgadas de altura, siete pies y seis pulgadas de ancho en los hombros, tres pies de grosor en el vientre, 
seis pies de ancho y cinco pies de grosor en la base. Pienso que estos bustos podrían ser obra de la actual generación; ésta, según estimo, alcanza unas dos mil personas. (ibidem)

Volvemos entonces al tema de ¿qué "generación" los construyó y sobre si son o no monumentales? Lo notable es que el mismo texto tiene lecturas contradictorias. Si es de la actual generación, la siguiente observación la desmiente:

Todos los monumentos que hoy día existen, y de los cuales el señor Duché ha hecho un dibujo muy exacto (atlas $\mathrm{n}^{\circ} 11$ ), parecen muy antiguos, se hayan en medio de deshechos, según se puede juzgar por la gran cantidad de osamentas que se encuentran cerca. Sin duda que su forma actual de gobierno no ha logrado igualar las condiciones de los antiguos, que no existe ya una autoridad tan considerable como para que un gran grupo humano se ocupe en erigirle una estatua, a fin de conservar su memoria. Estos colosos han sido substituidos por pequeñas pirámides de piedras cuya cúspide está blanqueada con agua de cal. (ibidem)

En relación a lo monumental, encontramos expresiones en ese sentido en Cook. Y cuando el capitán del navío L'Astrolabe Paul Antoine Fleuriot de Langle va al interior de la isla se encuentra con numerosos monumentos de dimensiones distintas a lo que observó Cook en la costa de Hanga Roa:

Varios estaban volcados, parece que estos pueblos no se ocupan de repararlos, otros estaban de pie con sus plataformas medio en ruinas. El más grande de los que medí tenía diez y seis pies y diez pulgadas de altura, incluyendo el capitel que tiene tres pies y una pulgada y que es de una lava porosa, muy liviana; su ancho, en los hombros, era de seis pies y siete pulgadas y su grosor, en la base, de dos pies siete pulgadas. (ibidem)

Si Cook y los Forster se maravillaban de Pascua por sus misterios, La Pérouse pondrá lo monumental a escala humana. Los signos ya no significan sino que representan. En primer lugar les quita toda dimensión cúltica: "no hemos visto traza alguna de culto ni creo que nadie pudiera tomar estas estatuas como ídolos, aunque estos indígenas muestran cierta veneración frente a ellas" (ibidem). También despoja a lo monumental de todo "arte" y grandeza:

Estos bustos de talla colosal, cuyas dimensiones ya se han señalado, prueban el poco progreso que han hecho en el terreno de la escultura, son de producción volcánica, de una piedra conocida por los naturalistas bajo el nombre de lapilli: es una piedra tan blanda y liviana que algunos oficiales del capitán Cook creyeron que podía ser artificial, compuesta por una especie de argamasa que se hubiera endurecido al aire. Sólo 
queda explicar cómo han logrado alzar, sin punto de apoyo, un peso tan considerable. Pero nosotros estamos ciertos que es una piedra volcánica muy liviana y que con palancas de cinco o seis toesas y deslizando piedras debajo, se puede, como explica muy bien el capitán Cook, lograr elevar un peso aún más considerable. Cien hombres bastan para esta operación: no habría espacio allí para el trabajo de un número mayor. De este modo lo maravilloso desaparece. (ibidem)

Si bien La Pérouse está atrapado por la "narrativa" de los viajeros, agrega una nueva dimensión: la asimetría en los vínculos (dar generosamente en oposición a robar) y cuya traducción geopolítica es la misma que la de Cook, claro que por otras razones. Veamos esto paso a paso. El robo, de los sombreros, aparece en la escena con los moai y es comentado por La Pérouse de la siguiente forma:

A la una de la tarde volví a la tienda con el propósito de subir a bordo. [...] Encontré allí a casi todos sin sombrero y sin pañuelos, nuestra mansedumbre había envalentonado a los ladrones y yo no había sido la excepción. Un indígena que me había ayudado a descender de una plataforma, luego de haberme hecho este servicio, me robó mi sombrero y se fugó a todo correr, seguido, como de costumbre, de todos los otros. Yo no lo hice perseguir y, ya que casi todos estábamos sin sombrero, no quise tener el derecho exclusivo de protegerme del sol. Continué examinando esa plataforma: es el monumento que me ha dado la más alta opinión de los antiguos talentos de este pueblo para la edificación, pues la palabra pomposa de arquitectura no conviene en este caso. (ibidem)

Dos horas más tarde La Pérouse es informado de un nuevo robo, de la reacción de la comunidad y de la protección que ella le dio a los "ladrones":

[...] dos buceadores habían cortado bajo el agua la cuerda que sostenía la canoa del Astrolabio, llevándose el gancho. [...] Dado que este gancho nos era necesario, dos oficiales y algunos soldados salieron en su persecución, pero fueron rechazados por una lluvia de piedras. Un tiro de fogueo al aire no hizo efecto alguno, de modo que se vieron obligados a disparar perdigones, algunos de los cuales seguramente alcanzaron a uno de ellos, pues las pedradas cesaron y los oficiales pudieron regresar tranquilamente al campamento. Fue imposible encontrar a los ladrones, los cuales deben de haberse extrañado de no haber podido vencer nuestra paciencia. (ibidem)

El tema del robo no respeta jerarquía, la comunidad entera se ve involucrada:

Algunos parecían tener una ligera autoridad sobre los otros, los tomé por jefes y les distribuí medallas que amarré a sus cuellos con una cadena. Pero pronto me di cuenta que estos eran precisamente los más 
insignes ladrones y que, aunque fingieran perseguir a los que robaban nuestros pañuelos, era fácil ver que lo hacían con la más decidida intención de no alcanzarlos. (ibidem)

Esta dimensión del robo (de no reciprocidad) se acrecienta para La Pérouse cuando se juzga a sí mismo como generoso y davidoso:

[...] hemos abordado su isla con el solo fin de hacerles bien: los hemos colmado de presentes, de cariño hacia los más débiles, especialmente los lactantes, sembramos en sus campos toda suerte de semillas útiles, dejamos en sus habitaciones cerdos, cabras y ovejas que seguramente se multiplicarán. Nada les exigimos a cambio. Sin embargo ellos nos lanzaron piedras y nos robaron todo lo que pudieron. (ibidem)

¿Los Rapa Nui no dan nada a cambio de lo recibido o "robado"? ¿No hay ningún intercambio? ¿No era ya un gran don el solo hecho de estar en el "ombligo del mundo o dieron algo? Dieron algo: sus mujeres y de una manera diferente a como lo hicieron con la expedición inglesa. Recordemos a Georg Foerster:

Entre ellos había una mujer, quien había llegado a bordo de la misma manera y llevó a cabo un particular tráfico propio. Visitó a varios de los oficiales inferiores y, a continuación se dirigió a los marineros, emulando las famosas hazañas de Mesalina.(G. Forster 1777: 183)

Ahora las cosas son diferentes. Cuando en la mañana desembarcan se produce una escena de intercambio:

Eran a lo menos ochocientos, entre los cuales había ciertamente al menos ciento cincuenta mujeres. El rostro de muchas de esas mujeres era agradable, ofrecían sus favores a todos aquellos que quisieran darles algún presente. Los indígenas nos instaban a aceptarlos: algunos dieron el ejemplo de los placeres que ellas podían procurar. Sólo estaban separados de los espectadores por una simple manta de género del lugar y durante los arrumacos de esas mujeres, robaban nuestros sombreros de nuestras cabezas y los pañuelos de nuestros bolsillos. (La Pérouse 1798)

Es notable que después que La Pérouse describe los robos sufridos en la mañana y a mediodía señale que los isleños: "volvieron a ofrecernos sus mujeres y quedamos tan amigos como en nuestra primera entrevista" (ibidem).

Estamos frente a un intercambio evidente y de apropiación del otro: de sus bienes, de su conocimiento ${ }^{20}$ y de su semen. ¿Captura del mana del otro vía el

20 "El cuidado que pusieron en medir mi buque me convenció de que ellos no consideraron nuestras técnicas como de seres estúpidos: examinaron nuestros cables, nuestras anclas, nuestra brújula, nuestro timón. Vinieron el día siguiente con una cuerda para volver a medir, 
intercambio sexual? ¿Las primeras relaciones sexuales con los europeos (en $1722,1770,1772)$ generaron una diferencia en los descendientes que ahora era necesario democratizar? ¿Había que ampliar el círculo del "cálculo salvaje”? Al ser el sistema de parentesco rapanui muy restrictivo -impide alianzas con los consanguíneos (de allí que ninguna de las tres estructuras elementales de parentesco sean aplicables) - ¿estimulaba la búsqueda de aliados "fuera" del círculo de los parientes, con lo cual la llegada de los tangata hiva fue visto como una suerte de "salvación"?

Los europeos aparecen así con nuevos signos y ese intercambio fue valorado negativamente por La Pérouse:

Los más desvergonzados tunantes europeos son menos hipócritas que estos isleños: todas sus zalamerías eran fingidas; sus fisonomías no expresaban ni un sólo sentimiento verdadero; el indígena menos confiable era aquel al cual veníamos de hacer un regalo y que parecía el más empeñado en rendir mil pequeños servicios. (ibidem)

Si para Cook la isla carecía de interés para el proyecto colonial, a igual conclusión llegaba La Pérouse: "para los navegantes esta isla presenta muy poco interés ya que no ofrece casi ninguna facilidad para los barcos" (ibidem). $\mathrm{O}$, en la palabra del Ingeniero en Jefe de la expedición, M. de Monneron:

Esta isla, por su posición fuera de todas las rutas de navegación, por su carencia absoluta de agua y de bosques y por la manera de ser de sus habitantes, que poseen la mejor voluntad del mundo para recibir y que están en la imposibilidad de dar algo, esta isla, digo, puede ofrecer un amplio campo para las especulaciones de médicos y de moralistas, pero no puede, en manera alguna, interesar a las diversas potencias marítimas de Europa. (ibidem)

\section{A modo de conclusión}

Si los moai eran un sistema de signos cuya agencia inmunizaba a la isla del exterior (la protección de los antepasados), con la llegada reiterada de tangata hiva la comunidad supo que se había iniciado una nueva era. Si los moai eran el corazón del orden, entonces a los tangata hiva había que hacerle un lugar (se iniciaba un nuevo escenario donde los moai serían puestos boca abajo). Los ingleses son los primeros testigos de la transformación de los monumentos en "ruinas" (en memoria, el pasado como presente). La isla se transformó en una "zona de contacto", ahí la relación con el otro es fundamental en la constitución de la identidad. Los rapanui darán una respuesta creadora, valiéndose de sus

lo que me hizo creer que habían discutido en tierra respecto de este asunto, habiéndoles quedado algunas dudas" (La Pérouse 1798). 
"valores tradicionales", de su "memoria pétrea", de su capacidad genealógica (que se vale del semen del otro para ampliarla, diversificarla) y de su capacidad escritural (de los petroglifos a los rongo-rongo).

$\mathrm{Si}$ en la zona de contacto los individuos "se constituyen en y a través de su relación mutua" (Pratt 2011: 34), si allí se producen "pérdidas, selecciones, redescubrimientos e incorporaciones" (Rama 1982: 39), hay que reconocer que esto es posible en la isla, fuera de ella los rapanui no han tenido, hasta ahora, la misma capacidad creadora. Posiblemente la respuesta a esta situación este en los sistemas de signos, en su aurea y agencia que hacen de la isla lo que es: Rapa Nui-Isla de Pascua.

\section{Bibliografía}

Aguera, Francisco Antonio. 1986. "Relación. En: Mellén (1986). Manuscritos y Documentos Españoles para la Historia de la Isla de Pascua: La Expedición del Capitán D. Felipe González de Haedo a la isla de David. Madrid: Colección Biblioteca CEHOPU, Cedes.

Anónimo. 1728. Tweejaarige Reyze door de Straat Magellanes en rondom de Wereld ter nader Ontdekkinge der onbekende Zuydlanden. Dordrecht: Joannes van Braam, Bockerkooper.

BARTHEL, T.S. 1956. Resultados preliminares del desciframiento de los KohauRongorongo de la Isla de Pascua. RUNA; Archivo para las Ciencias del Hombre VII(1956):233-241.

Behrens, Carl Friedrich. 1739. Histoire de L'Expédition de Trois Vaisseaux, envoyés par la Compagnie des Indes Occidentales des Provinces-Unies aux Terres Australes, en MDCCXXI, par Monsieur de B[...]. Tomo I, pp. 121-140. La Haya: Aux dépens de la Compagnie MDCCXXXIX (1739).

Bouman, Cornelis. 1994. The complete Journal of Captain Cornelis Bouman, Master of the ship Theinhoven, Forming part of the fleet of Jacob Roggeveen, from 31 March to 13 April 1722 During Their Stay Around Easter Island. Rapanui Journal, vol. 8, núm. 4, p. 95-100.

Campbell, Ramón y Jorge Silva. 1970. Hallazgo de un nuevo tipo de escritura de la Isla de Pascua. Anales del Museo de Historia Natural 3:161-191.

Cook, James. 1777. A voyage towards the South Pole, and round the world: performed in His Majesty's ships the Resolution and Adventure, in the years, 1772, 1773, 174, and 1775 / written by James Cook, commander of the Resolution. In which is included, Captain Furneaux's narrative of his proceedings in the Adventure during the separation of the ships. Illustrated with maps and charts, and a variety of portraits and views drawn during the voyage by Mr. Hodges, 2 vols. Londres: W. Strahan \& T. Cadell.

1938. Viaje hacia el polo sur y alrededor del mundo. Tres tomos Madrid: Espasa-Calpe. 
Diamond, Jared. 2007. Colapso. Por qué unas sociedades perduran y otras desaparecen. México: Randon House Mondadori.

Donoso N., Guido. 1987. El histórico viaje de Lapérouse. Atenea, núm.455, p. 11-50.

Edwards, Edmundo. Ms. s.f. Cuando el universo era una isla: arqueología y etnografía de Isla de Pascua o Rapa Nui.

Faba, Paulina. 2011. Valparaíso à Hanga Roa, du XIX au XX siècle: trajectoires de la patrimonialisation missionnaire de Rapa Nui (Île de Pâques). Histo-Art 4:321-342.

Fischer, Roger. 1997. Rongorongo. The Easter Island Script. History, Traditions, Texts. Oxford: Clarendon Press.

. 2005. Island at the end of the world. The turbulent history of Easter Island. Londres: Reaktion Books.

Flenley, John y Paul Bahn. 2002. The Enigmas of Easter Island. New York: Oxford University Press.

Foerster, Rolf. 2012. Rapa Nui, primeras expediciones europeas. La Construcción dialógica de Isla de Pascua (Siglo XVIII). Santiago: Rapanui Press.

Forster, George. 1777. A voyage round the world in his Britannis Majesty's sloop, Resolution, commanded by Capt. James Cook, during the years 1772, 3, 4 and 5 / by Georg Forster. 2 vols. Londres: F. White, J. Robson, P. Elmsly; and Robinson.

Forster, Johann Reinhold. 1982. The Resolution Journal of Johann Reinhold Forster. Editado por Michael E. Hoare. Londres: Hakluyt Society.

1996 [1778]. Observations Made during a Voyage round the World. Honolulu: Universty of Hawai'i Press.

Gell, Alfred. 1998. Art and Agency: An Anthropological Theory. Oxford: Clarendon Press.

González de Haedo, Felipe. 1986. Relación. En: Mellén (1986). Manuscritos y Documentos Españoles para la Historia de la Isla de Pascua: La Expedición del Capitán D. Felipe González de Haedo a la isla de David. Madrid: Colección Biblioteca CEHOPU, Cedes.

Harrison, John Park. 1874. The Hieroglyphics of Easter Island. Journal of the Royal Anthropological Institute of London 3 [discusión de la] lámina XXVII.

Hervé, Juan Antonio. 1986. Relación. En: MELLÉN (1986). Manuscritos y Documentos Españoles para la Historia de la Isla de Pascua: La Expedición del Capitán D. Felipe González de Haedo a la isla de David. Madrid: Colección Biblioteca CEHOPU, Cedes.

La Perouse, Jean François Galaup de. 1798. Voyage de La Pérouse autour du monde, publié conformément au décret du 22 avril 1791, et rédigé par M.L.A. MiletMureau, Général de brigade dans le corps du Génie, Directeur des Fortifications, ex Constituant, Membre de plusieurs Sociétés littéraires de Paris. 4 vols. París: Chez Plassan. 
Lévi-Strauss, Claude. 2006. Entrevistas con Claude Lévi-Strauss (George Charbonnier). Buenos Aires: Amorrortu.

Martínez, Sergio. 2012. La antropología, el arte y la vida de las cosas. Revista de Antropología Iberoamericana 7(2):171-195.

Mason, Peter. 2005. Siete maneras de ser moai. Boletín del Museo Chileno de Arte Precolombino" 10(2):9-27.

. 2012. Moai on the move. Journal of the History of Collectiones 24(1):117-130.

Mellén Blanco, Francisco. 1986. Manuscritos y Documentos Españoles para la Historia de la Isla de Pascua: La Expedición del Capitán D. Felipe González de Haedo a la isla de David. Madrid: Colección Biblioteca CEHOPU, Cedes.

1988. "La Isla de Pascua en el centenario de su incorporación a Chile". Revista de Marina, 105(785), 393-402.

. 1993. Interpretación Rapa Nui de los numerales escritos por los españoles en 1770. Revista Española del Pacífico 3:61-66.

. S.f. "Escritura jeroglífica rapanui en documentos españoles y signos rongorongo tardíos en tabletas ika"; utilizamos una versión que se encuentra en la Biblioteca Nacional de Santiago de Chile y que no tiene fecha; hay una versión en Internet (islasdelpacifico.wordpress.com/2013/02/26/ escritura-jeroglifica-rapanuien-documentos-espanoles-y-signos-rongorongo-tardios-en-tabletas-ika/) que da como referencia: "NAVIGARE NECESSE EST. Estudios de Historia Marítimaen Honor de Lola Higueras", pp. 395-413. Edición de Luisa Martín-Merás. Gijón: Fundación Alvargonzález (corregido en 2010).

Pratt, Mary Louise. 2011. Ojos imperiales. Literatura de viajes y transculturación. Buenos Aires: FCE.

Rama, Angel. 1982. Transculturación narrativa en América Latina. México DF: Siglo XXI.

Ricouer, Paul. 2008. Tiempo y narración. México: Siglo XXI.

Roggeveen, Jacob. 1838. Dagverhaal der Ontdekkings-reise van Mr. Jacob Roggeveen, met de schepen Den Arend, Thienhoven en De Afrikaansche Galei, in de Jaren 1721 en 1722. Middelburg: De Gebroeders Abrahams.

1908. Extract from the official log of the voyage of Mynheer Jacob Roggeveen, in the ships Den Arend, Thienhoven and de Afrikaanische Galei, in 1721/22, in so far as it relates to the discovery of Easter Island, 2(13). Cambridge: Hakluyt Society.

Rotledge, Katherine. 1919. The Mystery of Easter Island. Londres: Sifton, Praed \& Co. Ltd.

Sahlins, Marshall. 2008. Islas de historia. La muerte del capitán Cook. Barcelona: Gedisa.

Data recebimento: 30/10/2014.

Data aceite: 20/11/2014. 